\title{
Comment on the Concept of Labor under the Green Development Concept
}

\author{
Leifeng Wang and Weiwei Liu \\ Jingdezhen Ceramic University, Jingdezhen, Jiangxi 333403
}

\begin{abstract}
General Secretary Jinping Xi mentioned the green development concept in the important speech delivered at the $18^{\text {th }}$ session of the fifth plenary session of the CPC Congress, and he also mentioned the labor concept on many occasions. Then, how do people work? A clear answer is given in Marxism: people correctly deal with interpersonal relationship and the relationship between people and nature in labor. Thus, it can be seen that it is urgent to organically combine green development concept with people's labor. At present, labor is interpreted in the academia from different perspectives and there are a lot of results, but there is no study review of labor from the green development concept. Therefore, it is of great theoretical and practical value to comprehensively sort out the research results of labor and promote the in-depth study of labor concept under the green development concept.
\end{abstract}

Keywords: Green development concept; Labor concept; Review

\section{述评绿色发展理念下的劳动观}

\section{王否峰 刘伟伟}

( 景德镇陶瓷大学, 江西 景德镇 333403 )

摘要: 习近平总书记在十八届五中全会的重要讲话中涉及绿色发展理念, 同样在多个场合提到其劳动观, 人们怎样劳动 呢? 马克思主义给出了明确答案: 人们在劳动中正确处理人与人、人与自然之间的关系。可见, 急需把绿色发展理念与人们 的劳动有机结合起来。目前, 学界对劳动从不同角度进行了的解读, 也出现了不少成果, 但是还没有从绿色发展理念来对劳 动进行研究述评。因此, 认真梳理以往关于劳动的研究成果, 推动绿色发展理念下的劳动观的深入研究具有重要的理论意义 与实践价值。

关键词: 绿色发展理念; 劳动观; 述评

中图分类号: A81 文摘标识码: A

引言

绿色发展理念与劳动观都是习近平总书记的系列重要讲话, 同样, 也是马克思主义中的重要思想。为 了把绿色发展理念与劳动观二者有机统一, 研究述评了绿色发展理念下的劳动观。通过对相关材料的收集 与整理, 认识到学界虽对劳动从不同角度进行了的解读, 但令人遗憾的是, 还没有从绿色发展理念来对劳 动进行研究述评。因此, 认真梳理以往关于劳动的研究成果, 推动绿色发展理念下的劳动观的深入研究具 有重要的理论意义与实践价值: 其理论意义在于有助于我们加深对 “劳动” 内容的深刻认识, 更好地建设 社会主义和谐社会与生态文明社会, 以劳动托起中国梦; 其实践价值是有助于反省我国当前人们劳动中存 在的问题, 只有做到生态与劳动相结合, 才能实现自然、人与社会的和谐。

\section{1. 国内相关研究的学术史梳理及研究动态}

劳动是当代社会中的重要内容, 绿色发展视野下的劳动观核心是绿色与劳动的结合。十八大以来, 习 近平指出创造性劳动的理念; 十八届五中全会上习近平强调绿色发展理念。人们怎样劳动呢? 马克思主义 
给出了明确答案：人们在劳动中正确处理人与人、人与自然之间的关系。即习近平的中国梦 “要让中国人 民有更好的教育，更稳定的工作、更可靠的社会保障、更优美的环境、工作得更好、生活得更好等。”应 该看到, 党和国家高度重视劳动问题与生态问题, 但是随着工业化快速推进, 以破坏绿色环境来换取经济 效益的增长, 以不合理劳动带来的环境问题, 威胁着经济社会的永续发展, 破坏了人与自然的和谐。因此, 我们认为，把绿色发展理念与劳动有机结合起来，对美丽中国与绿色世界有着重要意义。

国内对劳动观的研究始于上世纪 80 年代中后期，主要集中阐述改革开放初期现实生活中劳动观念、 劳动行为的特点和内容。对绿色发展视野下的劳动观也略有提及, 但关注很少。1980 年代以来, 一批学者 开始从事绿色与劳动研究。中国大陆学者周穗明、冯颜利、陈学明、吴宁、汤建龙、陈永森、曹亚雄、蔡 华杰等的研究涉及劳动、生态等诸多方面:

传统文化中的劳动观。儒家在强调自然对人类影响的同时, 人也可以利用自然、影响自然, 提出了以 “天人合一” 为核心的和谐生态思想。比如儒家关于 “天地生万物”、“物我相亲” 的观点就反映了中国古 代劳动人民对人与自然之间关系的朴素认识; 墨家针对当时社会生存资源匮乏, 老百姓缺衣少食而统治阶 层的奢靡淫佚提出富民劳动思想。比如，墨子在《墨子・辞过》强调 “俭节则昌，淫佚则亡。” 意为节俭 才能昌盛，淫逸就会灭亡。

经典马克思主义的劳动观。学界概括了马克思主义劳动观的内涵, 指出五代领导人提出的劳动观是我 国建设生态文明社会的重要思想理论资源和实践指南, 具有针对性、一贯性、实践性等特征, 是我国社会 主义和谐社会的重要指导思想。如, 胡建在《论马克思 “劳动观” 的双重视角一一基于工业文明与生态文 明的不同立场》一文中指出: “马克思规定了 “劳动是人与自然之间的物质变换关系” 的内涵, 剖析出个人、 社会、人类三重视角中的人与自然的物质变换关系, 并提出了如何用生态文明生产方式妥善处理这三重关 系, 以解决劳动可持续性问题的见解”。

生态马克思主义的劳动观。韩秋红、杨赫姣在《高兹的生态理性一一社会主义的另一种阐释》一文中 探讨了劳动与消费的关系。高兹谈到了 “人们更少地劳动、人们消费得更好” 和人们把文化重新整合到其 日常生活中来” ${ }^{[2]}$; 徐艳梅的 《生态学马克思主义研究》一书, 分析了劳动与时间的关系。高兹的观点 是在目前劳动岗位日益减少的情况下，要实现劳动解放首先要减少劳动时间，但同时又要保证每个人都能 从事劳动 ${ }^{[3]}$; 温晓春的《安德烈 - 高兹医疗工业政治经济学批判的基本逻辑》一文, 阐述了资本劳动关系, 高兹强调市场关系与雇佣劳动是资本运动的结果, 消除医疗化必须消除资本运动 ${ }^{[4]}$; 陈永森在《生态社会 主义幸福观评析》一文中, 阐述了劳动与自由的关系。高兹提出劳动本身应该成为一种自主性的活动行为, 不能使劳动只成为挣工资的手段 ${ }^{[5]}$ 。

以往学界对劳动观的研究为今后本领域的研究奠定了一定的基础, 但还有待作进一步的提升: 一方面, 实现研究内容 “专”、“深” 化的提升。当前的研究介绍性、描述性的文章占了很大部分, 今后的研究应加 强实效性研究, 比如当前人们劳动的调查与分析, 尽量避免宏大叙事式研究, 应实现研究领域的专深化提 升。另一方面, 实现研究方法和视角转换的提升。当前的研究以定性说明的研究方法为主, 以伦理学、经 济学的视角为切入点的研究居多, 今后的研究可从多种视角如绿色发展的视角入手, 增加定量和实证分析, 以增加研究的可信性和实用性。 


\section{2. 国外相关研究的学术史梳理及研究动态}

在国外学术界, 从古典经济学到现代西方经济学的发展过程中, 劳动与生态自由始终是其研究的重要 内容, 主要形成以下三种观点:

劳动赞扬论。卢卡奇以劳动为本体, 认为作为类自由模式的劳动应该是社会存在与发展的理想模式是 实现 “劳动的合类性”与自由的结合。

劳动两端论。在布鲁诺看来，劳动是人类文明进化和人的尊严的基础，也是人的 “神圣化” 过程的基 础。劳动是和谐的, 其最高境界是劳动与闲暇的结合劳动是艰辛的, 人的 “神圣化” 过程具体体现在对艰 辛的忍受之中。

劳动反对论。以高兹、汉娜・阿伦特等人为代表, 认为劳动社会使人越来越走向劳动崇拜以及随之而 来的不自由。

国外研究成果无疑有其独特的学术视角和启发价值，但其劳动观的形成主要是以资本主义形成时期和 资本主义后工业化时期为背景, 从伦理学的视角为切入点加以研究, 由于思想和价值的多元化、国家背景 的不同以及关注点、研究方法的差异，他们的评判往往停留于门户之间，缺乏辩证分析。

综上, 就国内外整体研究而言, 学界对劳动观的研究为今后本领域的研究奠定了一定的基础, 但还 有待作进一步的提升, 本研究的学科价值在于: 从哲学、伦理学、心理学、美学、文学、艺术等传统人文 学科角度研究绿色发展视野下的劳动观, 这是一次前所未有的尝试; 此研究将初步建立一个以劳动为核心 的绿色发展体系, 填补我国哲学社会科学的一项空白。虽然国内外学术界对绿色发展理念下的劳动观的研 究都取得了一定成果, 但目前该领域研究仍存在很多不足。主要体现在: 第一, 目前的成果, 缺少一种对 劳动观学理探索和开创性研究, 缺少绿色劳动这样一门具有专门研究领域、范畴和方法的人文科学; 第二, 基本上还没有人专门从 “绿色发展理念下的劳动观” 角度去看生态文明的价值诉求。在这方面国内外都缺 乏相关著作和论文。有些著作或论文虽然涉及, 但还谈不上系统研究, 也没有凸显出 “劳动观” 对于解决 当今社会主义劳动问题与社会绿色发展的意义和价值。

\section{3. 小结}

中国传统有着源远流长的劳动思想, 西方国家在生态环境保护进程中也形成了不少劳动思想。为此, 我们将考察中国传统文化中的劳动思想 (儒家的劳动伦理思想、墨家的富民劳动思想等), 以及西方环境 保护思潮, 特别是生态马克思主义、生态社会主义思潮中有关生态劳动的思想 (“生态理性”、“从量的标 准到质的标准”、从 “资本逻辑” 走向 “生活逻辑”、“消费得越少而生活得越好”、“从劳动而不是从消费 中获得满足”等)，并指出这些思想对绿色发展理念下的劳动观建设的意义及其局限性。

党的十八大报告指出: “要构建和谐劳动关系; 要实施就业优先战略和更加积极的就业政策; 要解决 好人民最关心最直接最现实的利益问题, 努力让人民过上更好生活; 保持适度劳动, 保障合理休息权利的 落实无疑是劳动者的基本要求。” ${ }^{[6]}$ 习近平曾说过 “中国梦是要让中国人民有更好的教育, 更稳定的工作、 更可靠的社会保障、更优美的环境、工作得更好、生活得更好等。进一步说, 就是让中国人民过上更加富 裕、更有尊严的生活、实现每个人自由而全面的发展。” ${ }^{[7]}$

对中国来说, 在当前社会主义经济新常态的背景下, 学习与研究绿色发展理念下的劳动观, 比如活动 的多样性与劳动的创新性, 合理消费与采用生态技术等, 有助于人们从生态的角度看待劳动与重新认识劳 
动, 重视劳动的创造性。针对当今中国社会已出现了人们在劳动中破坏生态环境的现象。一些领域存在着 资本的驱动、存在着科学技术不够发达导致无法最大程度地利用自然资源的情况; 人们由于生存的需要和 一些人缺乏公益心, 破坏自然的现象大量存在等等。不仅造成了人力物力的浪费, 也给生态造成负担。我 们将研究当前劳动现象的特征、产生的原因及解决之道, 必将有助于全面建成小康社会与实现中华民族伟 大复兴的中国梦。

\section{致谢}

基金项目: 景德镇陶瓷大学社会科学研究项目 “高兹的劳动观及其当代启示” 的阶段性成果。

\section{Acknowledgement}

Fund Project: Periodical results of Jingdezhen Ceramic University Social Science Research Project "Gao Zizhi 's View of Labor and Its Contemporary Enlightenment".

\section{参考文献}

[1]胡建. 论马克思 “劳动观” 的双重视角——基于工业文明与生态文明的不同立场 $[\mathrm{J}]$. 中共宁波市

委党校学报, 2012, (1).

[2] 韩秋红、杨赫姣. 高兹的生态理性一一社会主义的另一种解释 $[J]$. 当代世界与社会主义, 2011, (2).

[3]徐绝梅. 生态学马克思主义研究 [M]. 北京: 社会科学文献出版社, 2007.

[4]温晓春. 安德烈 . 高兹医疗工业政治经济学批判的基本逻辑 $[\mathrm{J}]$. 兰州学刊, 2010，(1).

[5]陈永森. 生态社会主义幸福观评析 $[J]$. 社会主义研究, 2011，(4).

[6]中国共产党第十八次全国代表大会文件汇编 [M]. 北京: 人民出版社, 2012.

[7]习近平. 第十二届全国人民代表大会第一次会议上讲话 [N]. 人民日报，2013-03-18（A01）.

\section{作者简介：}

王否峰 (1979-), 男, 河南周口人, 博士, 景德镇陶瓷大学讲师, 主要研究方向: 马克思主义理论、生态社会主义 刘伟伟(1981-) 女, 河南信阳人, 景德镇陶瓷大学助教, 主要从事思想政治教育研究

\section{References}

[1] Hu Jian. On the Different Perspectives of Marx 's "Labor View" - Based on the Different Position of Industrial Civilization and Ecological Civilization [J]. Journal of Party School of CPC Ningbo Municipal Committee, 2012, (1).

[2] Han Qiuhong, Yang Hejiao. Gao Zi's ecological rationality - another explanation of socialism [J]. Contemporary World and Socialism, 2011, (2).

[3] Xu Yanmei.Study of Ecological Marxism [M]. Beijing: Social Science Literature Publishing House, 2007.

[4] Wen Xiaochun. Andre. Gao Zi's basic logic of political economy criticism of medical industry [J]. Lanzhou Journal, 2010, (1).

[5] Chen Yongsen, An analysis of ecological socialism happiness view [J]. Socialism Research, 2011, (4).

[6] Compilation of the Eighteenth National Congress of the Communist Party of China [M]. Beijing: People's Publishing House, 2012. 